\title{
Atrial Premature Complex by ECG Finding
}

National Cancer Institute

\section{Source}

National Cancer Institute. Atrial Premature Complex by ECG Finding. NCI Thesaurus. Code C62257.

An electrocardiographic finding of an ectopic impulse originating in the atria and not specifically in the sinus node. The P wave morphology of these complexes is often different from a sinus $\mathrm{P}$ wave and the RR intervals preceding these complexes is also shorter than those of the regular beats. (CDISC) 